\title{
Supporting climate change vulnerability and adaptation assessments in the Asia-Pacific region: an example of sustainability science
}

\author{
John Hay $\cdot$ Nobuo Mimura
}

Received: 1 March 2006/ Accepted: 10 May 2006/ Published online: 26 August 2006

(C) Integrated Research System for Sustainability Science and Springer-Verlag 2006

\begin{abstract}
Sustainability is achieved only when there is full reconciliation between: (1) economic development; (2) meeting, on an equitable basis, growing and changing human needs and aspirations; and (3) conserving the limited natural resources and the capacity of the environment to absorb the mulitple stresses that are a consequence of human activities. The linkages between climate and sustainability are examined in the context of both the wider Asia-Pacific region and local level climate risks and adaptation responses. These findings are used to underpin and illustrate several implications for sustainability science. Climate change is seen as both an impediment to increasing sustainability and as an opportunity, though in most cases the former far outweighs the latter. Assessments of climate change vulnerability and risk are shown to be of critical importance because they inform decisions as to where resources for adaptation are best invested. They also show whether global efforts to reduce greenhouse gas emissions need to be strengthened because of limits to adaptation. In practice, adaptation takes place at many levels, essentially ranging between tangible interventions at community and enterprise level and national and international efforts to strengthen the enabling environment for adaptation. It is informative to undertake regional assessments of adaptation, even though most adaptation interventions need to reflect local conditions, including local adaptive capacities. The foregoing findings, based in part on a series of regional and local case studies, lead to several recom-
\end{abstract}

J. Hay $(\bowtie) \cdot$ N. Mimura

Institute for Global Change Adaptation Science,

Ibaraki University, Mito City, Japan

e-mail: johnhay@ihug.co.nz mendations for further research that will help reduce barriers to implementing responses that reduce climate related risks, including adverse consequences for sustainability. The recommendations relate to such themes as making optimum use of predictive capabilities, characterising the linkages between climate change and sustainability, implications of the required rates and magnitudes of adaptation, institutional responses that enhance adaptive capacity, use of new and traditional technologies, the multiple dimensions of social responsibility, and enhancing the enabling environment for adaptation at the community and enterprise level. If these recommendations are acted upon they will, in turn, help address much needed improvements in quantifying the costs and benefits of adaptation, prioritising adaptation options, assessing sustainable development tradeoffs, and monitoring the success of adaptation initiatives. Such improvements will have even greater utility if they are incorporated into user-friendly decision support tools for adaptation.

Keywords Vulnerability · Adaptation · Risk · Sustainability $\cdot$ Asia $\cdot$ Pacific

\section{Introduction}

Current climate variability and extremes, and the anticipated longer-term changes in climate, represent a major impediment to enhancing, let alone achieving, sustainability (Swart et al. 2003). Sustainability is achieved only when there is full reconciliation between: (1) economic development; (2) meeting, on an equitable basis, growing and changing human needs and aspirations; and (3) the limited natural resources 
and the capacity of the environment to absorb the multiple stresses that are a consequence of human activities.

The many dimensions of sustainability make it highly challenging to provide planners, decision makers and other key players with the scientifically credible and policy relevant information that will improve the quality of decision making to enhance environmental, social and economic outcomes. In recent decades there have been major advances in short-term and seasonal weather forecasting and in long-term climate modeling, allowing for early warning and longer-term planning. This increasing emphasis on proactive rather than reactive responses is placing greater demands on climate science to provide targeted guidance that recognises such key challenges as the complexity of climatesustainability interactions, the scale dependencies of stresses and responses, and residual uncertainties.

This paper examines the linkages between climate and sustainability (Beg et al. 2002; Markandya and Halsnaes 2002), in the context of both the wider AsiaPacific region and local level climate risks and adaptation responses. These findings are used to underpin and illustrate the implications for sustainability science (Kates et al. 2000), leading to several recommendations for further research that will lessen the ways in which climate extremes, variability, and change impact adversely on sustainability.

\section{Climate change and sustainability: threats and opportunities}

As Schipper and Pelling (2006) highlight, direct economic, physical and human disaster losses constitute the mainstay of disaster impact assessments, yet these incorporate only a fraction of total loss. From a purely economic standpoint, direct losses are often overshadowed by indirect impacts, e.g. the result of lost production time or market share, and by secondary losses, which are felt by the regional or national economy, such as increased debt or inflation. Disasters cause distortion in national budgets, moving resources away from capital expenditure towards relief and rehabilitation (Benson and Clay 2004). Indirect costs imposed by health problems can result from damaged homes and utilities, extreme temperatures, contaminated food, polluted water, debris- and mud-borne bacteria, and mildew and mould. However, the societal costs of climate-related disasters are typically quantified in terms of property losses and human deaths. Post-event impacts on coastal businesses, families and neighbourhoods, public and private social institutions, natural resources, and the environment generally go unrecognised in disaster cost accounting. Finding an accurate way to document these unreported or hidden costs is a challenging problem that has received increasing attention in recent years. Studies are now confirming that family roles and responsibilities after a disastrous coastal storm undergo profound changes associated with household and employment disruption, economic hardship, poor living conditions, and the disruption of pubic services such as education and preventative health care.

Development can be made more sustainable by increasing the ability of systems and societies to adapt to multiple stresses, including climate change and climate variability. For example, the millennium ecosystem assessment (MEA 2005) describes the many and growing human-induced stresses being placed on natural ecosystems and resources. Climate change is projected to exacerbate the loss of biodiversity and increase the risk of extinction for many species. Water availability and quality are projected to decrease in many arid and semiarid regions. The risk of floods and droughts is projected to increase and sea level is projected to rise. The reliability of hydropower and biomass production is projected to decrease in some regions. The incidence of vectorborne diseases (e.g. malaria, dengue fever) and of waterborne diseases (e.g. cholera) is projected to increase in many regions, and so too are heat stress mortality and threats of decreased nutrition in other regions, along with severe weather traumatic injury and death. Agricultural productivity is projected to decrease in the tropics and sub-tropics. There are projected adverse effects on fisheries. Projected changes in climate during the twenty-first century are very likely to be without precedent during at least the past 10,000 years and, combined with land use change and the spread of exotic or alien species, are likely to limit both the capability of species to migrate and the ability of species to persist in fragmented habitats (MEA 2005).

\section{Climate change: a threat to sustainability}

Until recently, attention has tended to focus on climate change materialising as longer term trends in average conditions, such as temperature, rainfall and sea level. Now there is growing realisation that the implications of climate change for sustainability in the Asia-Pacific region are likely to be driven by changes in climate variability, including extreme events (Benson and Clay 2004; van Aalst 2006). Moreover, observed data are already revealing trends in extreme events that are 
consistent with those projected to occur as a consequence of climate change (Gulledge 2006; Bettencourt et al. 2006). For both the Indian and Southwest Pacific Oceans a significant increase in the number and proportion of hurricanes reaching categories 4 and 5 has been observed over the past 35 years (Webster et al. 2005). This change is consistent with the observed increased in sea surface temperatures. However, the number of cyclones and cyclone days has decreased.

Figure 1 shows the large number of damaging wind storms occurring in the Asia region, and the increasing occurrence in both Asia and Oceania (CRED 2005; Munich Re 2005). With the exception of the United States and Mexico, all of the top ten countries impacted by wind storms are in Asia. The Pacific Islands Region suffers fewer natural disasters than Asia, but the economic costs can again be high, especially for cyclones, both in absolute terms and as a percentage of the gross domestic product. These relatively rare, but high cost (in social as well as economic terms) events obscure any trends in the economic losses (Fig. 2).

High resolution global climate models are increasing the confidence with which projections of future changes in extreme climatic events, such as heat waves, heavy rainfall and typhoons, can be made. For example, the frequencies of extreme high temperatures and heavy rainfall events in Japan are expected to increase during the present century (Fig. 3 and Hasumi and Emori 2004). In the Asia-Pacific region as whole, floods, droughts, damaging winds, extreme high temperatures, and high sea levels and surface temperature are likely to occur with increased frequency. These conditions will, in turn, impact adversely on human health, agriculture, fisheries, water resources, infrastructure such as roads and buildings, services such as transport and communication, and on economic activities such as tourism. As a result, economic development and social progress will in most cases be slowed, and sometimes even reversed, if only temporarily.

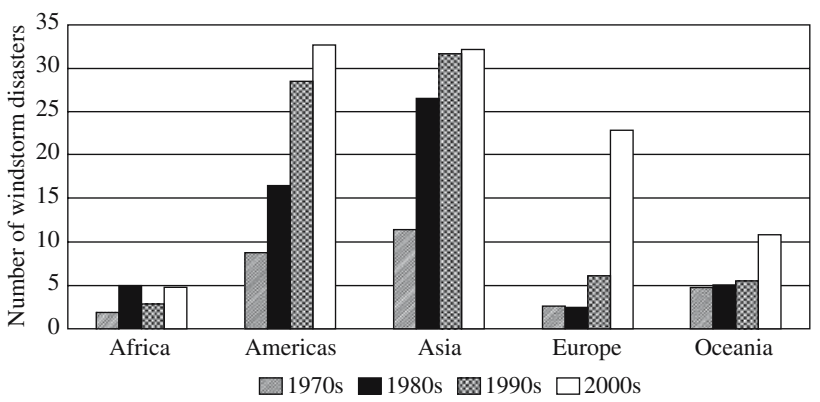

Fig. 1 Trends in windstorm disaster occurrence by region: 1970 2005. Source: CRED (2005)
Responding to climate change: opportunities to enhance sustainability

While climate change clearly impedes progress towards the elusive goal of sustainability, it also provides opportunities. Firstly, as illustrated in Fig. 4, it is possible to reduce the economic and associated costs of climate-related disasters through proactive interventions. Over the period 1950-2004, the annual number of tropical cyclones and typhoons making landfall in Japan showed no significant trend (Fig. 4a). There is high interannual variability, with a record ten tropical cyclones making landfall in 2004. However, the number of the port-related disasters in Japan, including those due to high waves and storm surges by typhoons, decreased between 1950 and 1999 (Yoshikura 2000) (Fig. 4b). This is attributed to increased protection against these disasters. However, not all damage costs can be avoided by such protection. Annual average restoration expenditures over the period still amounted to US\$240 million. Nevertheless, a key message from this example is that addressing climate-related risks proactively is often beneficial, even if the climate does not change. The most desirable adaptive responses are those that augment actions that would be taken even in the absence of climate change, due to their contributions to sustainable development (Hay et al. 2003). Where adaptation leads to the less pressure on natural resources, improved environmental management and enhanced social well-being of the poor, not only is vulnerability to climate change reduced, but such measures also contribute to sustainable development.

Secondly, climate change may in a few instances enhance the sustainability of human activities. For example, warmer conditions would likely reduce human hardship during winters in North Asia and North East China while the fertilizing effect of higher concentrations of atmospheric $\mathrm{CO}_{2}$ could enhance forest growth rates. However, such increases in

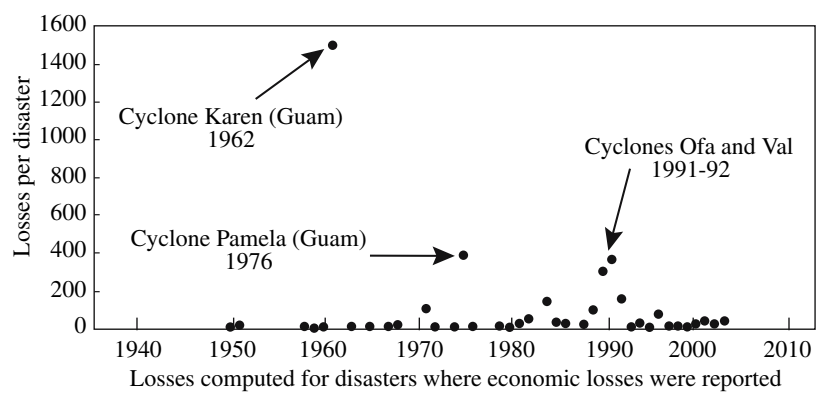

Fig. 2 Trends in losses per disasters reported in the Pacific Islands Region [in millions of constant (2004) US\$] 1950-2004 (Bettencourt et al. 2006) 
Fig. 3 Number of days $>30^{\circ} \mathrm{C}$

(left) and rainfall $>100 \mathrm{~mm} /$

day (right) for Japan

predicted by MIROC-hi

(Hasumi and Emori 2004)
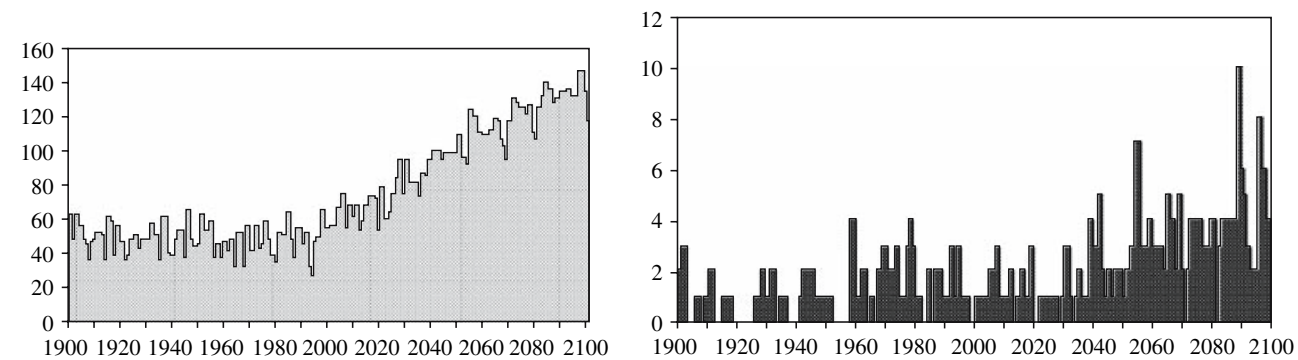
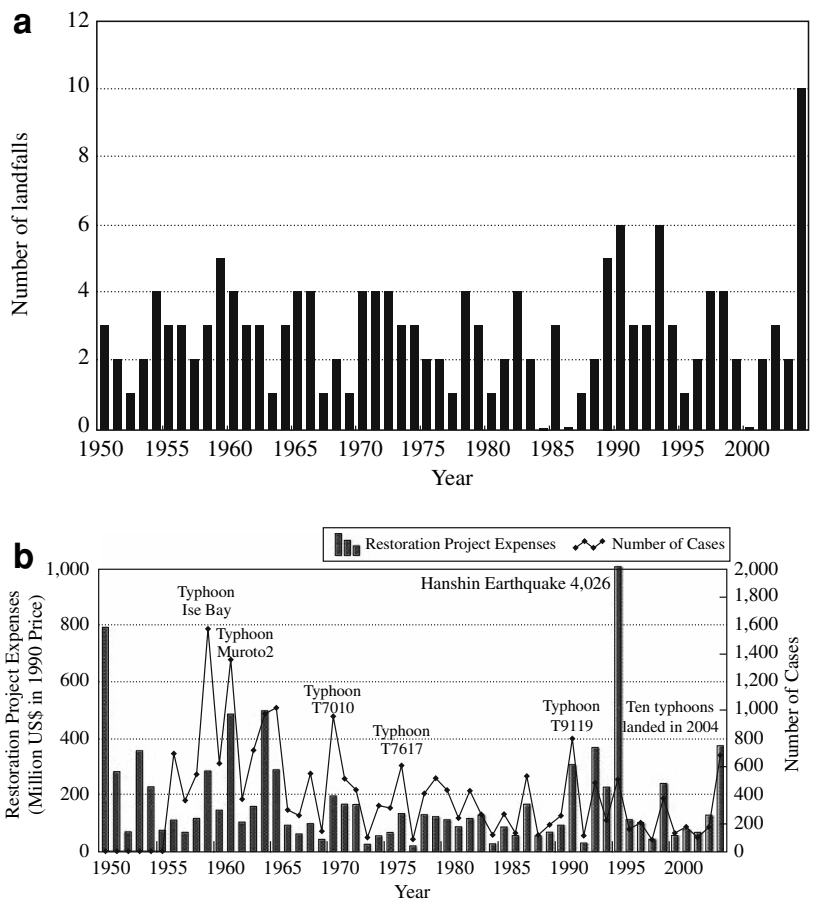

Fig. 4 a Annual number of tropical cyclones and typhoons with landfalls in Japan, 1950-2004 (Munich Re 2005). b The number of occurrences and the cost of damage for port-related disasters in Japan, 1950-2004 (Data: Port and Harbour Bureau, Ministry of Land, Infrastructure and Transport)

productivity may well be tempered by additional stresses, such as those resulting from a warmer climate, ozone pollution, drier conditions and insufficient nitrogen supply. Warmer climate can also introduce new vectors and pathogens that could cause serious health hazards (Patz et al. 2005).

\section{Climate vulnerability and risk in the Asia-Pacific region}

For both natural and human systems, including society, climate vulnerability is the potential to be harmed by atmospheric hazards. Climate risk considers not only the potential level of harm but also the likelihood that such harm will occur. Assessments of vulnerability and risk are of critical importance; not only do they inform decision making regarding requirements for adaptive responses to climate change but they may also show whether efforts to reduce greenhouse gas emissions (i.e. mitigation) need to be strengthened because of the limits to adaptation.

Regional assessments of vulnerability

Because of its geographical and social diversity, the Asia and Pacific region will be affected by climate change in a variety of ways, including impacts on water resources, terrestrial and marine ecosystems, agriculture, coastal zones, infrastructure, and industries (IPCC 2001). Temperature increase and shifts in rainfall are likely to induce significant reductions in agricultural productivity, in spite of the fertilizing effect of increased atmospheric concentrations of $\mathrm{CO}_{2}$. This productivity decline will be exacerbated by soil degradation (Faisal and Parveen 2004). Flooding can also have a significant impact on rice crop production (IPCC 2001).

Climate change will impose more stresses on the ecosystems of the boreal forests, mountains and highlands of Asia. Glacial melt in the Himalayas will also be accelerated by global warming. It is already appearing to causes serious problems due to the formation of glacier lakes and the risk of downstream flooding. Low-lying deltas and small islands will be greatly affected by climate change and sea-level rise, which causes large-scale inundation along the vast Asian and Pacific coastline, erosion of sandy beaches, and adverse impacts on mangroves and coral reefs.

Another concern in this region is changes to tropical cyclones. Maximum tropical cyclone intensity is likely to increase $5-10 \%$ by around 2050 . This would be accompanied by an increase in mean cyclone intensities (Walsh 2004). As a result, peak cyclone-related precipitation rates are also estimated to increase by $25 \%$. These changes are all strongly influenced by the El Niño-southern oscillation (ENSO). The multiple actions of these changes in sea level and extreme events will certainly bring about serious effects on the 
security of human society in the region (Mimura 2001). Even today, the areas below high tide level and storm surge level (i.e. inundated and flooded areas) are $0.48 \%$ and $0.94 \%$ of the total land area of the Asia and Pacific region, respectively. This will increase to $0.98 \%$ and $1.32 \%$ with a $1 \mathrm{~m}$ sea-level rise. Regarding the numbers of affected people, today about 47 million people, or $1.21 \%$ of the total population, live in the area below high tide level, while 270 million people or $5.33 \%$ live below storm surge level. These figures show that the Asia and Pacific region is already vulnerable to storm surge-induced flooding. With a $1 \mathrm{~m}$ sea-level rise, and allowing for population growth, the number of people affected by 2100 increases to 200 million and 450 million people, respectively. The most severely affected areas are likely to be the deltas of the Mekong, Ganges and Brahmaputra, and Yangtze rivers, and the southern part of Papua New Guinea. More than $10 \%$ of the national population is affected in countries such as Vietnam, Cambodia, Bangladesh, and the small island countries in the Pacific. These findings show how closely the effects of changes in climate, including its variability, are related to the region's sustainability.

Area-specific assessments of climate-related risks

The climate risk profile (ADB 2006) is becoming increasingly recognised as a valuable tool for use by planners and decision makers with responsibilities to reduce climate-related risks to acceptable levels. An example of a climate risk profile is provided in Fig. 5. The present day risks (attributed to the year 2000) are

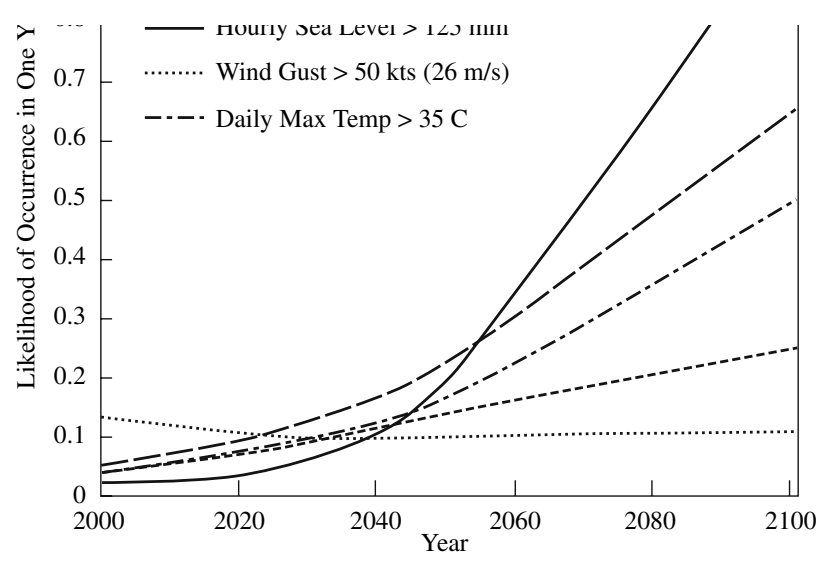

Fig. 5 Climate risk profile for Pohnpei, Federated States of Micronesia (ADB 2006) determined by analysing extreme events in recently observed climatic data and calculating return periods and thence probabilities. In some instances the length of the historic record makes it is possible to show how risk levels have varied in the recent past (Fig. 6). Future levels of risk (Figs. 5, 6) are determined using the output of one or more global climate models and designated greenhouse gas emission scenarios. Uncertainties in future levels of risk can also be determined, but are not shown here. The uncertainties arise from differences in greenhouse gas emission scenarios and in variations between models for the projected changes in climate.

In general, the likelihood component of a climaterelated risk will be applicable over a larger geographical area, as well as to many sectors. This is due to the spatial scale and pervasive nature of weather and climate. Thus the likelihood of, say, an extreme event or climate anomaly, is often evaluated for a country, state, small island or similar geographical unit. While the likelihood may well vary within a given unit, there is often insufficient information to assess this spatial variability, or the variations are judged to be of low practical significance. On the other hand, the consequence component of a climate-related risk will normally be site- or sector-specific. Conveniently, climate-related damage costs integrated over a given time period into the future, say 50 years, combine both the likelihood and consequence components of risk. In this regard, Table 1 shows the calculated damage costs due to flooding as a result of heavy rainfall and storm surge or elevated sea levels for two Pacific Island communities. Baseline conditions are provided by the no climate change case, with the additional costs attributable to climate change being the difference in

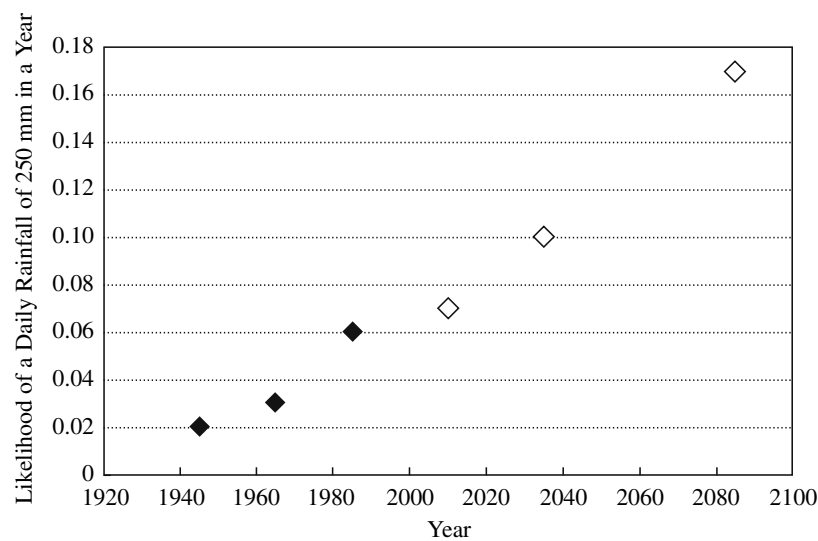

Fig. 6 Likelihood of a daily rainfall of a least $250 \mathrm{~mm}$ in any year, for Rarotonga, Cook Islands. Black symbols Analysis of observed data, open symbols based on global climate model output (ADB 2006) 
Table 1 Flood damage costs (for a discount rate of 3\%) for two Pacific Island Communities, integrated over two time periods, with and without climate change (CC). From ADB 2006

\begin{tabular}{|c|c|c|c|c|}
\hline \multirow[t]{2}{*}{ Location and source of flooding } & \multicolumn{2}{|c|}{$\begin{array}{l}\text { Time integrated damage } \\
\text { costs to } 2050\end{array}$} & \multicolumn{2}{|c|}{$\begin{array}{l}\text { Time integrated damage } \\
\text { costs to } 2100\end{array}$} \\
\hline & No CC & With CC & No CC & With CC \\
\hline \multicolumn{5}{|l|}{ Avatiu-Ruatonga (Cook Islands) ${ }^{\mathrm{a}}$} \\
\hline Heavy rain & 13.04 & 13.72 & 16.38 & 18.64 \\
\hline Sea surge & 30.77 & 40.75 & 26.48 & 40.49 \\
\hline \multicolumn{5}{|c|}{ Sapwohn $(\text { Federated States of Micronesia })^{b}$} \\
\hline Heavy rain & 9.99 & 15.59 & 12.55 & 23.01 \\
\hline High sea levels & 5.51 & 5.72 & 6.92 & 7.38 \\
\hline
\end{tabular}

${ }^{a}$ NZ\$ Million

${ }^{\mathrm{b}}$ US\$ Million

damage costs between the two cases. In the examples shown, damage costs attributable to climate change are large in some instances (e.g. heavy rain in Sapwhon) and minor in others (e.g. heavy rain in Avatiu-Ruratonga). Such results thus highlight the need for location- and area-specific analyses of climate-related risks.

Implications for sustainability

The foregoing findings, as well as more comprehensive assessments such as IPCC (2001), show that, both regionally and at specific locations, current climate variability and extremes impose untenable social, environmental and economic costs on both natural and human systems, through such events as flooding, salt water intrusion, wind damage and drought. Importantly, such costs are typically distributed inequitably, preferentially affecting the poor and other vulnerable groups. For these reasons alone, it is important to explore and undertake actions to adapt to current climate extremes and variability, both to deal with today's problems and as an essential step to building long-term resilience to withstand the impending changes in climate. To date, a failure to grasp the real and pervasive costs of climaterelated disasters has made it difficult for policy and decision makers to gain support for diverting scarce resources from one part of the national, enterprise or community budget, in order to support disaster reduction and other adaptation programmes. Moreover, uncertainties in climate change risk estimates and, even more so, in the likely success of adaptive responses, have often been judged too large for adaptation to be incorporated into national development planning in a meaningful way (Bettencourt et al. 2006).

There is now hard evidence that climate extremes, variability and change are significant impediments to successful economic development-i.e. they represent risks to regional, national and local economies (ADB 2006; Dilley et al. 2005). This highlights the need to ensure that disaster reduction management and adaptation are integral components of the national risk management strategy and, in turn, of the national development planning process. Many disaster and climate change response strategies are the same as those that contribute in a positive manner to sustainable development, sound environmental management, and wise resource use. They are also appropriate responses to climatic variability and other present-day and emerging stresses on social, cultural, economic and environmental systems.

\section{Adaptation: reducing vulnerability and risk, and enhancing sustainability}

At the most basic of levels, adaptation to climate change can be achieved in five ways:

- By reducing the likelihood of an adverse event or condition, e.g. by improving catchment management, thereby avoiding excessive runoff and hence flooding;

- reducing consequences, e.g. by ensuring healthy reef and mangrove systems, which act as buffers during a storm surge;

- redistributing (i.e. sharing) the risk, e.g. through insurance schemes;

- avoiding risk, e.g. through land use planning that regulates construction in hazardous areas;

- accepting risk, which amounts to the "do nothing, at least for now" adaptation option.

All but the last adaptation options not only address climate change but also have clear sustainable development benefits. 
Regional assessments of adaptation

Given the substantial potential impacts of climate change and sea-level rise for most of the Asia-Pacific region, a proactive approach to reducing such risks, through adaptation, is seen as increasingly important. When it is appropriately planned and implemented, adaptation can reduce the vulnerability to climate change by increasing societies' capacity to respond to the impacts. IPCC (2001) identifies specific adaptation strategies for countries for relevant sectors in the Asia-Pacific region, including food security, disaster preparedness and management, environmental management, and human health. An important perspective is that adaptation should pursue "no regrets" measures and "win-win" options. As well as increasing economic efficiencies, this helps to ensure that adaptation is mainstreamed in the wider national policy framework.

While countries in the Asia-Pacific region have a long history of adapting to various environmental changes, they have been mostly reactive. People in the region have recognised and utilised the resilience of their environments. For example, coasts of the Pacific Islands are surrounded mostly by coral reefs and mangrove forests. This natural system has provided highly effective protection to the coasts, and is thus a source of resilience. Therefore, the most serious implication of climate change and sea-level rise is that they damage these systems, thereby reducing the natural resilience of small Pacific islands. On the society side, resilience is enhanced by the strong community ties that provide mutual support to individuals and families, particularly when a community faces a crisis such as the serious damage that follows a tropical cyclone. History shows that the societies of the Pacific Islands have not been passive, yielding to the effects of environmental changes including climate variability. Rather, they adapted to the changes in an active manner. Lessons learnt from such history will give examples for future planning of adaptation to climate change and sea-level rise in this century (Nunn and Mimura 2006).

There are many other examples of local resilience and community-based adaptive capacity in the AsiaPacific region (e.g. Mirza et al. 2005; Obura 2005; Nakalevu et al. 2006). Given the effectiveness of such traditional social and cultural capacity to cope with environmental changes, it is important to appropriately evaluate and incorporate these factors into future adaptation strategies and planning.
Local examples of adaptation

While it is possible, and informative, to undertake regional assessments of adaptation, the fact that climate risks and impacts are generally area- if not site-specific requires that adaptation interventions reflect local conditions. Local differences in the capacity to adapt reinforce this situation, adaptive capacity being the ability of natural and human systems to evolve in ways that accommodate climate changes or to expand the range of variability and extremes with which they can cope (Jones 2001; Yohe and Tol 2002). Within a given country adaptation thus takes place at many different levels, essentially ranging from tangible interventions at the community and business enterprise level on the one hand and, efforts to enhance the enabling environment for adaptation on the other, the latter being largely the responsibility of central government.

In Samoa, Saoluafata is one of the communities most vulnerable to coastal hazards such as flooding, erosion and landslides, but especially to coastal erosion. The impact of high storm surges and sea-level rise is already evident, with approximately $30 \mathrm{~m}$ recession of the coastline. The main option for adaptation is relocation, but for cultural reasons this is considered to be undesirable. However, recent infrastructure development projects have highlighted the willingness of the community to adapt, in that recently a new school was constructed further inland. Roads have been extended inland, and improved, for easy access by the community. As a result, other community assets have started to redevelop inland. Members of the community are also working together to upgrade and improve their coastal springs. The project aims at improving water quality, and the availability of water for community consumption. The coastal springs have provided for the community during droughts and after natural disasters. However, increasingly frequent and severe high storm surges and flooding events have reduced the quality of these springs, affecting the health of the community, especially children.

Among the many natural disasters that strike Bangladesh, cyclones are considered to be of the greatest concern due to their devastating nature, including the potential for high numbers of human casualties. Although Bangladesh has suffered from cyclones for centuries, comprehensive disaster management commenced only with the disastrous cyclone of 1991. Accommodation and reduction of risk are now the main strategies advocated by the government, and have become widely accepted amongst people at the 
grass-root level. Due to the high population density and shortage of land, retreat is not possible and to date has not been supported by the government. Rather, the government has given equal importance to both structural as well as non-structural adaptation measures. These include:

Structural measures:

- Construction of additional multi-purpose, multistorey concrete structures as secular communityowned buildings, e.g. community centres, primary schools, health centres, to act as cyclone shelters rather than structures specifically for cyclone refuge;

- Construction of earthen embankments along the coast and increasing the height of existing embankments;

- Construction of flood-proofed access routes to cyclone shelters (Fig. 7);

- Planting forest all along the coast (Fig. 8); and

- Building community based earth-mounds (locally called Killa) for livestock.

Non-structural measures:

- Prepare and implement relevant legislation, policies and plans;

- Improve local communities' knowledge of how cyclones strike by teaching the history of cyclones in Bangladesh, when and where they strike and how people can protect themselves, etc;

- Undertake community-based dialogues for the precautions that should be taken to protect livestock, assets and houses, at para (a small community of several households) level;

- Improve the accuracy and timing of cyclone warnings by adopting a system of sequenced warnings; and

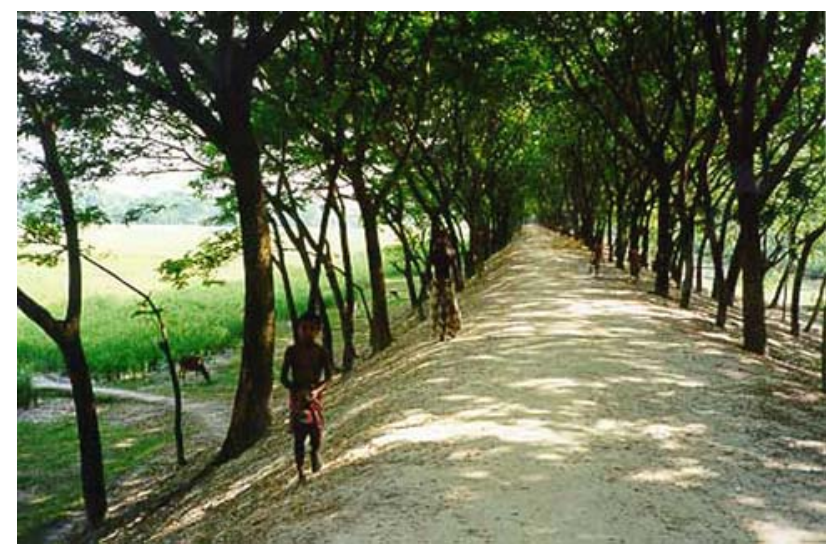

Fig. 7 A typical cyclone-proofed access route in the south-west coastal region of Bangladesh (Photo: M. Karim)

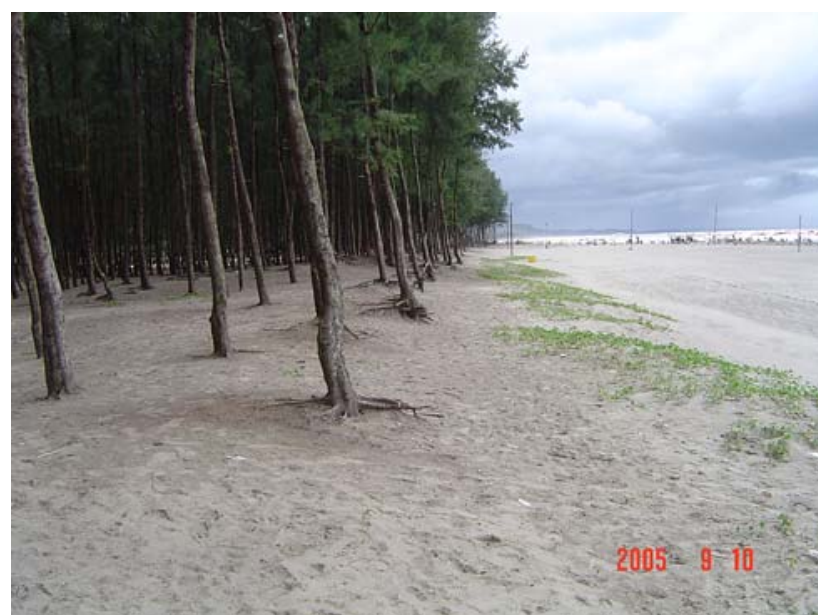

Fig. 8 Plantation along the Cox's Bazar Beach in the south-east coastal region (Photo: M. Karim)

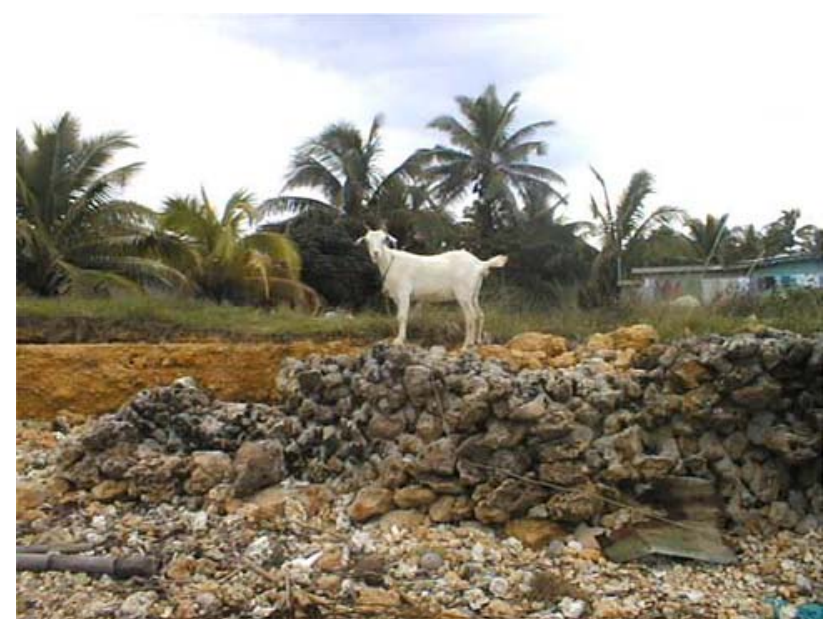

Fig. 9 Part of the degraded seawall protecting the village of Yadua-storm waves penetrate into the land behind the damaged sea wall and erode the coastal flat on which the village lies (Photo: Patrick Nunn, Fiji)

- Encourage communities to undertake practice exercises, to test the capacity of existing cyclone shelters to accommodate all residents.

For decades the villagers of Yadua, on the south (windward) coast of Viti Levu Island, Fiji, have been affected by erosion of the low-lying coastal sand flat on which their village lies. The problem has become particularly acute since the late 1970s. Their first response was to build a seawall, a construction made largely from rocks taken off the fringing coral reef. However, the seawalls repeatedly collapsed over the next 15 years (Fig. 9). Finally the villagers realised that this was not a viable long-term option for shoreline protection. In the late 1990s the people of Yadua were persuaded that replanting the mangrove fringe along 
the most rapidly eroding shorelines was the best option. After several false starts this project is now well underway. Replanted mangroves now cover an area of some $1,500 \mathrm{~m}^{2}$ and the mangrove nurseries from which the juveniles are planted out are now full. The project is being embraced enthusiastically by the villagers, although they realise that it will take around 25-30 years before a significant mangrove forest is in place.

There are a number of challenges facing the inhabitants of Aitutaki (Cook Islands) today. Many of these challenges are likely to be aggravated by climate change. The island is economically vulnerable to climate change impacts, especially on tourism and coastal areas. A community vulnerability and adaptation assessment identified availability of drinking water resources as the most pressing concern, due to changing rainfall patterns resulting in increased drought and in salt water intrusion into the ground water. In the future these problems are likely to be exacerbated by a combination of non-climate and climate factors. Addressing these changes is requiring a range of adaptation strategies that emphasise practical, small-scale initiatives that can be undertaken at the levels of individual households and small businesses. However, adaptation strategies can be successful only if they have the support and understanding of the whole community. Adaptation options identified through community and other consultations include rainwater harvesting, mains leak reduction, hydroponics for agriculture when the groundwater is salty, changing housing and bank loan policies to facilitate purchases of rainwater storage tanks, desalinisation or other appropriate technology, and education and awareness about water conservation. The priority adaptation option was rainwater harvesting and household tanks. These are now being installed for all households and small business enterprises.

\section{Implications for sustainability science}

The preceding sections have highlighted the overwhelming adverse consequences climate change has on the sustainability of human activities and the resulting need for assessments of climate vulnerability and risks and of adaptation options. If such assessments are to result in planning outcomes and decision making that reduce climate risks to acceptable levels, and increase sustainability, a number of current shortcomings need to be addressed. These are identified in the following sections, along with indications as to how sustainability science can remedy the current deficiencies.
Making optimum use of predictive capabilities

Historically, adaptation to the extremes, variability and trends of climate has changed to be reactive, due to the absence of any meaningful predictive capability. Today, the ability to predict future changes in the climate makes it possible for adaptation to be proactive. If adaptation is reactive, as opposed to planned, the range of response options is likely to be fewer and adaptation may well prove more expensive (ADB 2006), socially disruptive and environmentally unsustainable. Moreover, many disaster and climate change response strategies are the same as those which contribute in a positive manner to present-day efforts to implement sustainable development, including enhancement of social equity, sound environmental management and wise resource use. Such adaptation addresses both the present-day and emerging stresses on social, cultural, economic and environmental systems. "No regrets" adaptation strategies are beneficial and cost effective, even when the consequences of climate change are not factored into the cost-benefit assessments.

Two key challenges for sustainability science are how to make best use of the increasing ability to predict climate futures and how to deal with the uncertainties that will always occur. The uncertainties are due, in part, to the complex interactions within and between the climate system and the associated environmental, economic and social systems, and also because of gaps in the information required to specify current conditions, the starting point for the predictions.

Characterising the links between climate change and wider sustainability

While the ability to describe future climates has increased in recent decades, there has not been a concomitant improvement in our understanding as to how changes in the climate system impact on the sustainability of both natural and human systems. In many cases the direct links are known and understood, while the downstream effects, or indirect links, are less well known at best. For example, environmental conditions, including ecological integrity and the health and productivity of the natural environment, are increasingly recognised as important underlying determinants of human health. Human health impacts are likely to result from 'downstream' and 'flow-on' effects from climate change impacts in other areas, such as reduced quality and quantity of water supplies, loss of coastal resources, reduction in 
ecosystem productivity and decline in agricultural productivity. At least from a human point of view, human health could be seen as an endpoint of primary impacts in these other areas.

Potential first order, or direct, health effects of climate change include deaths, injuries, illness and discomfort caused by changes in average temperature and thermal extremes, as well as deaths and injuries caused by more frequent and more intense cyclones, storms and floods. Second order, or indirect, effects are those mediated through ecological and environmental factors and include increased incidence rates of vector-borne diseases (such as dengue fever and malaria), waterborne diseases (such as viral and bacterial diarrhoea) and diseases related to toxic algae (such as ciguatera fish poisoning). Nutrition-related illnesses may be considered as second order effects but also fall into the category of higher order and cumulative effects. More diffuse and less well-defined higher order health impacts would also include those arising from climate change impacts that lead to increases in poverty, homelessness, unemployment, economic instability and other forms of social disruption, such as forced migration.

While direct effects are usually easier to define, describe and link to climate variability and change, the higher order effects are more diffuse and difficult to research and document. However, the latter could be more important in terms of the overall public health impact of climate change and the burden of disease caused by climate impacts.

Implications of the required rates and magnitudes of adaptation

To date, our understanding of appropriate adaptation responses is very limited, due in part to the fact that only recently has there been formal recognition of the importance of changes in climate extremes and of the possibility of abrupt climate change. Adaptation science (considered here to be a branch of sustainability science) is now faced with the challenge of identifying adaptation responses that address a wide spectrum of rates of change, from slow to fast, and from subtle changes to extreme events. Moreover, if scarce resources are not to be squandered, the magnitude of adaptation required to address climate change will also vary, with responses being optimised to the anticipated or actual conditions. For example, the capability to adapt will vary between ensuring adequate response by an individual and the need for centralised initiatives to move large numbers of people, perhaps even the entire population of a country.
Institutional responses that enhance adaptive capacity

Institutions, and their associated policies, are one of the three key dimensions of adaptation to climate change. The others are technology and social/ behavioural change. While there is growing recognition of the importance of institutions to successful adaptation, much more research is required in order to identify the most appropriate institutional (e.g. country or sector) arrangements for a given situation. Effective and efficient institutions, especially governmental institutions, are an important part of the enabling environment for adaptation. Institutional capabilities and cooperation are perhaps key in this respect. Climate change, including identification and implementation of appropriate technology-based adaptation responses, is often a new and intimidating area of responsibility for government officials. For this and other reasons there is often a tendency to defer to colleagues in environment and related ministries who have more experience, at least at a general level. The resulting scattered and uncoordinated approach to such a pervasive issue as climate change is often far from optimal.

No one institutional set-up to oversee policy development and implementation related to climate change will be appropriate to all countries, but working with the "right" institutions is critical. To date, many adaptation efforts have had limited success because they have been overseen, and often implemented, by junior or weak ministries that are ineffective in influencing key ministries such as public works, finance and health (Bettencourt et al. 2006). The challenge is therefore to develop methods that will help identify an appropriate institutional mix for a given situation, and specifically one that will maximise economies of scale and minimise external influences.

The multiple dimensions of social responsibility

Climate change raises many issues related to equity. Identifying and resolving these issues is a challenge that calls for committed and collaborative efforts by all the sciences, not just the social sciences. For example, most individuals would agree with the principle that any climate-related risks that present generations may find unacceptable must not be imposed on future generations-this is one aspect of intergenerational equity. However, distinguishing between acceptable and unacceptable risks is particularly challenging, in part because the boundary will depend on such complex factors as adaptive capacity, previous experience 
with climate-related hazards and future values and expectations. Thus, to be equitable, adaptation policy needs to take into account that countries in the developing world will be more affected by climate change than industrialised countries, in part due to higher vulnerabilities (e.g. small island states) but also to lack of capital and capacity to adapt to climaterelated impacts.

Strengthening the operational links between risk characterisation and risk management

Conventional assessments of the need for, and nature of, adaptation interventions have focussed on identifying the potential impacts of climate change and then, in a giant leap of faith, identifying and recommending one or more adaptation initiatives. A risk-based approach to adaptation helps overcome this problem. Risk assessment and management have evolved into a continuum where there are strong and direct linkages between risk characterisation and risk management. However, considerable effort needs to be directed toward adapting the generic approaches and tools of risk assessment and management so they can usefully support the adaptation process. Some progress has already been made, with case studies and good practice guidelines becoming available, such as those in ADB (2006).

Enhancing the enabling environment for adaptation at community and enterprise level

The majority of direct adaptation initiatives will be undertaken at the enterprise and community level; their success will very much depend on the supportive nature of the "enabling environment". This comprises the high level and robust systems and capabilities that foster the adaptation process, including innovation, revitalisation of traditional knowledge and practices, application of human knowledge and skills, policies, financing, legislation and regulations, information, markets and decision support tools. It encourages and supports the "climate proofing" of development projects and related initiatives, as well as being supportive of the wider sustainable development process. Longerterm initiatives at national and sub-national levels are required to create and strengthen the enabling environment.

To date there is inadequate understanding as to which specific attributes of the enabling environment are critical to the success of adaptation at the community and enterprise level. Once these key determinants have been identified, the next challenge will be to establish and apply methods for optimising the enabling environment. While the optimal mix of attributes might well vary, for example, from location to location or sector to sector, the task will be to identify the characteristics of the enabling environment that provide the best backing for all adaptation initiatives being supported.

Prioritising and selecting adaptation options

As adaptation science increases its ability to deliver the information and understanding required by decision makers, there will be increasing calls for more rigorous prioritisation and selection of adaptation measures, based on costs and benefits, including non-monetary components. Such assessments will be made not only in the narrow context of managing climate-related risks, but also, as capabilities improve, in terms of the implications for sustainable development. Inevitably there will be tradeoffs, not least of which is deciding whether to allocate funds to adaptation now, or to defer to some time in the future.

Development of user-friendly decision support tools for adaptation

As the complexity of decision making increases, as implied in the preceding section, so too will the need and demand for decision support tools. These will make use of the methodologies referred to above, but will package them in a way that ensures a flow of policy-relevant information and knowledge to decision makers.

\section{Summary and conclusions}

This paper has examined the links between climate and sustainability in the context of climate risks for the wider Asia-Pacific region and at a local level, and of adaptation responses designed to reduce those risks. The links between climate and sustainability are numerous and, in many cases, highly complex, especially when both direct and indirect effects are considered and allowance is made for the many factors infuencing feedbacks. Current climate variability and extremes, and the anticipated longer-term changes in climate, represent a major impediment to enhancing, let alone achieving, sustainability. They impose untenable social, environmental and economic costs on both natural and human systems, through such events as flooding, heat waves, salt water intrusion, wind damage and drought. Importantly, such costs are 
typically distributed inequitably, preferentially affecting the poor and other vulnerable groups. Thus, in most instances, climate change threatens to reduce sustainability, although in some instances climate change may enhance sustainability (e.g. benefits to forest-dependent communities due to increased growth rates).

In the Asia-Pacific region, vulnerability to climate change, including the specific risks, highlights the close relationship with the sustainability of the region at large, at national as well as at local levels. More specifically, climate extremes, variability and change are significant impediments to successful economic development, and contribute to human hardship and poverty. Floods, droughts, damaging winds, extreme high temperatures, and high sea levels and surface temperature are likely to occur with increased frequency. These conditions will, in turn, impact adversely on human health, agriculture, fisheries, water resources, infrastructure such as roads and buildings, services such as transport and communication, and on economic activities such as tourism. Economic development and social progress will in most cases be slowed, and sometimes even reversed, if only temporarily.

Development can be made more sustainable by increasing the ability of systems and societies to adapt to multiple stresses, including climate change and climate variability. As a result it is important to explore and undertake actions to adapt to current climate variability and extremes, recognising that this is the most appropriate preparation for dealing with future changes in climate. All appropriate adaptation options, with the exception of the "do nothing" response, have clear sustainable development benefits. Adaptation should pursue "no regrets" measures and "win-win" options. As well as increasing economic efficiencies, this helps to ensure that adaptation is mainstreamed in the wider national policy framework.

While countries in the Asia-Pacific region have a long history of adapting to various environmental changes, such adaptations have been mostly reactive. People in the region recognised and utilised the resilience of their environments. However, in recent decades there have been major advances in short-term and seasonal weather forecasting and in long-term climate modeling. These developments have enabled both early warning and longer-term planning. The increasing emphasis on proactive rather than reactive responses is placing greater demands on climate science to provide targeted guidance that recognises such key challenges as the complexity of climate-sustainability interactions, the scale dependencies of stresses and responses, and residual uncertainties.
The foregoing findings have numerous implications for sustainability science. These include taking advantage of the growing ability to predict climate change, including reduced uncertainties, thereby allowing a transition from reactive to proactive adaptation initiatives. All disciplines involved in sustainability science have major roles to play in ensuring effective decision making to reduce climate risks to acceptable levels, with a concomitant increase in sustainability.

Acknowledgments This paper has benefited substantially from information provided by Mohamed Karim (Ibaraki University), Patrick Nunn (The University of the South Pacific), Violet Wulf (Samoa) and the Ports and Harbours Bureau, Ministry of Land, Infrastructure and Transport, Japan. The authors also acknowledge, with thanks, the Integrated Research System for Sustainability Science, including financial assistance to participate in the First International IR3S Symposium. This paper is a product of that involvement.

\section{References}

ADB (2006) Climate proofing: a risk-based approach to adaptation. Asian Development Bank, Manila

Aalst MK van (2006) The impacts of climate change on the risk of natural disasters. Disasters 30(1):5-18

Beg N, Morlot JC, Davidson O, Afrane-Okesse Y, Tyani L, Denton F, Sokona Y, Thomas JP, La Rovere EL, Parikh JK, Parikh K, Rahman AA (2002) Linkages between climate change and sustainable development. Clim Policy 2:129-144

Bettencourt S, Croad R, Freeman P, Hay J, Jones R, King P, Lal P, Mearns A, Miler G, Pswarayi-Riddihough I, Simpson A, Teuatabo N, Trotz U, Van Aalst M (2006) Not if but when: adapting to natural hazards in the Pacific Islands Region. A policy note. Pacific Islands Country Management Unit, East Asia and Pacific Region, World Bank

Benson C, Clay EJ (2004) Understanding the economic and financial impacts of natural disasters. disaster risk management series, vol 4. World Bank, Washington

CRED (2005) CRED Crunch. Centre for Research on the Epidemiology of Disasters (CRED), Université catholique de Louvain, Brussels

Dilley M, Chen U Deichmann RS, Lerner-Lam AL, Arnold M, Agwe J, Buys P, Kjekstad O, Lyon B, Yetman G (2005) Natural disaster hotspots: a global risk analysis. Synthesis report, World Bank, Washington

Faisal I, Parveen S (2004) Food security in the face of climate change, population growth, and resource constraints: implications for Bangladesh. Environ Manage 34:487-498

Gulledge J (2006) Global fingerprints of greenhouse warming: a summary of recent scientific research. Pew Centre on Global Climate Change, Washington

Hasumi H, Emori S (eds) (2004) K-1 coupled model (MIROC) description, K-1 technical report, 1. Center for Climate System Research, University of Tokyo

Hay JE, Mimura N, Campbell J, Fifita S, Koshy K, McLean R, Nakalevu TP, Nunn P, de Wet N (2003) Climate variability and change and sea-level rise in the Pacific Islands region. A resource book for policy and decision makers, educators and other stakeholders. South Pacific Regional Environment Programme. Ministry of the Environment, Japan 
IPCC (2001) Climate change 2001, impacts, adaptation and vulnerability. Cambridge University Press, London

Jones RN (2001) An environmental risk assessment/management framework for climate change impact assessments. Nat Hazards 23:197-230

Kates RW, Clark WC, Corell R, Hall JM, Jaeger CC, Lowe I, McCarthy JJ, Schellnhuber HJ, Bolin B, Dickenson NM, Faucheux S, Gallopin GC, Gruebler A, Huntley B, Jaeger J, Jodha NS, Kasperon RE, Mabogunje A, Matson P, Mooney H, Moore B III, O'Riordan T, Svedin U (2000) Sustainability science. Science 292:641-642

Markandya A, Halsnaes K (2002) Climate change and sustainable development: prospects for developing countries. Earthscan, London

MEA (Millennium ecosystem assessment) (2005) Ecosystems and human well-being: synthesis. Island Press, Washington

Mimura N (2001) Distribution of vulnerability and adaptation in the Asia and Pacific region, Global Change and Asia Pacific Coasts. In: Proceedings of the APN/SURVAS/LOICZ joint conference on coastal impacts of climate change and adaptation in the Asia-Pacific region, pp 21-25

Mirza MMQ, Patwardhan A, Attz M, Merchand M, Ghimire M, Hanson R (2005) Flood and storm control. In: Chopra K, Leemans R, Kumar P, Simons H (eds) Ecosystems and human well-being: policy responses, vol 3, pp 337-352

Munich Re (2005) Topics geo annual review: natural catastrophes 2004, Munich Re

Nakalevu T, Carruthers P, Phillips B, Saena V, Neitoga I, Bishop B (2006) Community-level adaptation to climate change: action in the Pacific. In: Proceedings of the regional workshop on community-level adaptation to climate change,
Suva, March 2005. Secretariat to the Pacific Regional Community (SPREP), Apia, Samoa

Nunn PD, Mimura N (2006) Promoting sustainability on vulnerable island coasts: a case study of the smaller Pacific Islands. In: McFadden L (ed) Managing coastal vulnerability: an integrated approach, Chap. 6. Elsevier, Amsterdam (in press)

Obura DO (2005) Resilience and climate change: lessons from coral reefs and bleaching in the western Indian Ocean. Estuar Coast Shelf Sci 63:353-372

Patz JA, Campbell-Lendrum D, Holloway T, Foley JA (2005) Impact of regional climate change on human health. Nature 438:310-317

Schipper L, Pelling M (2006) Disaster risk, climate change and international development: scope for, and challenges to, integration. Disasters 30:19-38

Swart R, Robinson J, Cohen S (2003) Climate change and sustainable development: expanding the options. Clim Policy 3S1:S19-S40

Walsh K (2004) Tropical cyclones and climate change: unresolved issues. Clim Res 27:77-83

Webster PJ, Holland GJ, Curry JA, Chang H-R (2005) Changes in tropical cyclone number, duration, and intensity in a warming environment. Science 309:1844-1846

Yohe G, Tol RSJ (2002) Indicators for social and economic coping capacity-moving toward a working definition of adaptive capacity. Glob Environ Change Hum Policy Dimens 12:25-40

Yoshikura K (2000) On port-related hazards of 1999 (in Japanese). Wave Beach 145:32-38 